\title{
Mathematics teacher education programs: practice and research
}

\author{
João Pedro da Ponte
}

Published online: 21 September 2012

(c) Springer Science+Business Media B.V. 2012

Mathematics teacher education involves a wide variety of processes and issues. Usually, the main focus of attention in this field of research is mathematics teachers themselvesespecially their knowledge, conceptions, beliefs, attitudes, competences, practices, and identity. Much attention has been put on the processes by which individual teachers or teachers in communities learn or acquire new knowledge, develop or change their practice or identity, and show new attitudes or competencies. However, mathematics teacher education, besides being a field of research, is also a field of practice. Many institutions across the world-universities, teacher colleges, normal schools and other public and private organizations-have programs that prepare prospective teachers who will teach mathematics in one school level or another. Often, these institutions also have interventions aimed at practicing teachers. Besides, the range of institutions and programs providing professional development opportunities for practicing teachers is even more diverse and the landscape is quickly changing with the increasing offer of e-learning distance education courses. Therefore, it is important to consider how mathematics teacher education programs are working, both for prospective and practicing teachers, how their quality is assured, what problems they face, and how they are changing to meet new societal demands.

In a review of literature about prospective teacher education, Ponte and Chapman (2008) suggest that the aspects of teacher education programs to take into account include (1) program instructors and other participants such as "mentors and students involved in the prospective teachers' field experiences" (p. 226) and (2) program elements such as

teaching approaches, purposes and objectives, curriculum and materials, assessment instruments and procedures, and the overall organization and pedagogical features of the program (e.g., ways of working/learning emphasized, personal relationships between preservice teachers and other participants, access to resources, and use of ICT). (p. 226)

J. P. da Ponte $(\bowtie)$

Instituto de Educação, Universidade de Lisboa, Lisbon, Portugal

e-mail: jpponte@ie.ul.pt 
It is interesting to look at the four articles in this issue of JMTE from the point of view of the teacher education program instructors and program elements. Two of the articles deal with prospective teacher education, one at elementary and the other at middle and secondary school levels. The article by Joanna Masingila, Dana Olanoff and Dennis Kwaka addresses the mathematics preparation of prospective elementary school teachers and puts its main focus on the program and the instructor. Whereas the data comes from a large number of institutions - a sample of 825 institutions in the USA with prospective elementary teacher education - the focus in rather specific, looking at the mathematical preparation of prospective teachers and the preparation and support provided to instructors. The results do not indicate good news. Most of the programs surveyed do not have the minimum of nine credits of mathematics content recommended by several independent bodies. There are several weaknesses in the preparation of the teaching staff of these programs, as most instructors do not have teaching experience at elementary level nor had opportunities to reflect in a deep way about important ideas in elementary mathematics. In addition, most of these instructors did not have specific training or support for their work as elementary mathematics teacher educators. Mathematics seems to have relatively little importance in the plans of study of these programs and the mathematics teaching staff seems to be underprepared and under supported to carry out its role in an efficient way.

The other article with a focus on a teacher education program, in this case a single institution, is that of Julie Gainsburg. The institution involved is a USA university with a mathematics credential program for middle and secondary school mathematics teachers. This is a post-baccalaureate program with student teaching in the final two semesters, a one semester mathematics methods course, and two mathematics student teaching seminarswhich can hardly be seen as a strong preparation in mathematics and mathematics education. The paper addresses the program in an indirect way, aiming to identify the factors that supported or constrained the graduates' use of the practices emphasized in the program in their professional activity. These practices are aligned with the curriculum recommendations of "reform mathematics." Drawing on results based on observations and interviews of 19 graduates of the program, the study suggests that their uptake of the program recommendations was limited. It advocates a strong emphasis in practical training accompanying the teaching of general concepts and stresses the need to have available a wide range of curriculum materials and scripts. In addition, it indicates that both the university and the employing school play very important roles and should work together. It also suggests that microteaching and rehearsal methods should be emphasized in teacher education and schools should encourage the induction of new teachers in communities of practice. This original case study of an ongoing teacher education program, carried out with a rather critical stance, shows that many of the practices encouraged by the program were valued by the graduates and some of them had a significant presence in their teaching practice leading the author to conclude that the improvements to make would require neither complicated nor revolutionary changes to teacher education.

The two other articles focus on practicing teachers. One of them is the article by Chandra Orrill and Rachael Brown that is based on an existing professional development program aimed at improving middle school teachers' mathematics knowledge. The program has a particular interest on problems in which it is possible to use many strategies to find a solution as well as on using technology and drawn representations. The main aim of the study is to know how participants make sense of situations involving proportional relationships when they have the opportunity to do extensive work with a specific representation, the "double number line." The 13 participants (who were teachers of grades 4-8) met $3 \mathrm{~h}$ per week for 14 weeks in a computer laboratory. The time in the sessions 
(called "classes") included working in groups on investigations and working individually on investigations just by themselves or with a partner. During the collective discussions, the facilitator was described as having a minimal role and relying heavily on participants' interactions. The course activities, stressing investigations, and collective discussions seem clearly aligned with what we may term an "exploratory approach". Assessment of teachers' knowledge was based on pre- and posttests, which provided interesting data for researchers. The results of this study indicate both the pieces of knowledge that appeared to be of significance in solving proportional problems and the pieces of knowledge that created obstacles to teachers making sense of the situations. These pieces of knowledge are considered to be relevant to get a deeper understanding of the nature of the teachers' knowledge. However, when the results are considered within the context of the participants working for an extended time on a single mathematics topic, one may not expect anything else but a significant teacher learning on this domain. Of course, the issue is to know how much of that learning is going to play a visible role in subsequent classroom practice and support enhanced students' learning.

Finally, the setting of the article by Raymond Bjuland, Maria Luiza Cestari, and Hans Erik Borgersen is a 2-year developmental and research project, conducted by a Norwegian university. This project sought to promote communities of inquiry with teachers from eight schools and university researchers (called "didacticians"). For the teachers involved, the activities of the project included sixteen workshops in a 3-year period. Phase 1 was devoted to "community building," in which participants got to know each other and learn to communicate, phase 2 addressed thinking about inquiry and classroom planning, and phase 3 focused on the schools' own goals for development. The workshops lasted for three and a half hours and had a consistent four-step structure with introduction, small group work on mathematics, small group work on teaching issues, and collective discussions. A very interesting feature of the program was that the teachers were organized in school teams that conducted meetings in their schools, with the participation of the researchers, to plan classroom activities based on the ideas presented in the workshops. Specific features of this program are its long-term duration, the strong participation of a group of researchers, and also its special funding. The goal of the article is to identify evidence of the development of the professional identity of a single teacher and identify indicators of the mathematics teacher identity for participation in different work situations. As one would expect, the authors provide evidence that this teacher's participation in a so extended and intensive project supported the development of her professional identity.

The four articles depict a variety of situations. The articles by Masingila, Olanoff and Kwaka, and Gainsburg address programs that already exist seeking to study their features and discuss their consequences for teacher preparation. The article by Orrill and Brown also draws on an existing course, but considers it essentially as a research site. Finally, the article by Bjuland, Cestari, and Borgersen is more of a report on a research project with a developmental side than a study of a teacher education setting that could possibly be replicated by others all over the world. Nevertheless, it suggests specific features that could possibly be adopted in regular teacher education programs. In general, there is a great variety of program features in the four papers ranging from the little importance ascribed to mathematics teaching in prospective elementary teacher education institutions to a concern with reform-oriented practices in the middle and secondary school credential programs, and ranging from a self-contained professional development course to the development and research project that seeks to establish deep connections with schools. There is also a wide variety of instructors playing their roles in these programs that range from the 
underprepared teacher educators in the USA to the group of didacticians that was able to work on the Norwegian project.

Taken together, these articles suggest that we need a continuous attention to program features, including study plans, the nature of the participants' activity, the relation between mathematics content, and mathematics teaching pedagogy, the relation to actual classroom practice, and its insertion in the school culture. Despite the huge amount of work already done in mathematics teacher education, we have just scratched the surface, and much more is still to be done.

\section{Reference}

Ponte, J. P., \& Chapman, O. (2008). Preservice mathematics teachers' knowledge and development. In L. English (Ed.), Handbook of international research in mathematics education (2nd ed., pp. 225-263). New York, NY: Routldge. 